\title{
The new low shear viscosimeter LS300 for determination of viscosities of Newtonian and non-Newtonian fluids
}

\author{
Peter Ruef ${ }^{1,2}$, Jutta Gehm ${ }^{3}$, Lothar Gehm ${ }^{3}$, Claudia Felbinger ${ }^{1}$, Johannes Pöschl ${ }^{1}$ \\ and Navina Kuss ${ }^{1}$ \\ ${ }^{1}$ Department of Pediatrics, Clinic of Neonatology, University of Heidelberg, Germany \\ ${ }^{2}$ Clinic of Pediatrics, SLK-Kliniken Heilbronn GmbH, Heilbronn, Germany \\ ${ }^{3}$ Expert Office of Rheology, Bad Homburg, Germany
}

\begin{abstract}
The low shear viscometer LS300 permits measurements of viscosity with the same precision of the LS30 but is now fully controlled by the windows based software. That allows to determine viscosity at several shear rates and to establish flow curves enabling determination of the viscosity of non-Newtonian fluids. The viscosity of whole blood of ten adults was determined via flow curves approximated by Casson. The sensitivity of the LS300 was evaluated by determining the viscosity of water at rising temperatures and by establishing flow curves of ten specimen of the same blood sample.
\end{abstract}

Key words: Flow curve - Viscosity — Non-Newtonian fluids - Casson

The low shear viscosimeters LS30/LS40 and with its latest development, the LS300 is sought-after in mineral oil industry, the cosmetic and food industry and in hemorheology, too. The technique of these devices based on the Couette principle (Fig. 1) was described as golden standard technique (Pop et al. 2004) and most useful (Ernst et al. 1985) for determination of blood viscosity at single shear rates for the preceding models of the LS300. The new LS300 (KSPV-4, Rheomed $\mathrm{GmbH}$, Aachen, Germany) is now fully controlled by the LS300 software and enables the operator to establish flow curves. Shear rate and viscosity are directly related to the properties of the fluid. Non-Newtonian fluids are governed by a non-linear relationship between shear stress and shear rate, whereas the viscosity of Newtonian fluids is independent from shear rate (Fig. 2), as indicated by the linear relation between shear rate and shear stress (Papaioannou et al. 2005). These flow curves can be approximated by mathematical models, which allow calculating the viscosity of a non-Newtonian fluid like whole blood (Shi et al. 1996; Baskurt et al. 2003; Marcinkowska-Gapinska et al. 2007).

Correspondence to: Peter Ruef, Department of Pediatrics, Clinic of Neonatology, University of Heidelberg, Im Neuenheimer Feld 430, D-69120 Heidelberg, Germany

E-mail: peter.ruef@t-online.de
The LS300 (proRheo GmbH, Althengstett, Germany) is a rotational rheometer based on the Couette principle (Fig. 1), equipped with a rotating measuring cup and a fixed measuring element. Thus, the measurements are not influenced by the Taylor vortex. The measuring principle is the same as the LS30 previously described (Aarts et al. 1984). The material number of the cup and the bob is steel (EN 1.4571).The radius of the measuring cup is $6 \mathrm{~mm}$, the radius of the bob is $5.5 \mathrm{~mm}$ and the length of the bob is $8 \mathrm{~mm}$. The sample volume was $0.9 \mathrm{ml}$. The bob was always covered with the tested sample. The software LS300 regulates the rotation count of the measuring cup. The number of measuring points at several shear rates and time may be selected as desired. The thermostat of the LS300 works with cryoregulation; its accuracy is $\pm 0.1^{\circ} \mathrm{C}$. The new technology of LS300 permits determination of shear forces at multiple shear rates during a single measuring run, over a wide range of shear rates from 0.018 to $125 \mathrm{~s}^{-1}$ (in steps of $0.01 \mathrm{~s}^{-1}$ ). By graphic presentation of shear rate versus shear stress one obtains data points which, when connected to each other, yield a flow curve (Fig. 3). The viscosity of non-Newtonian fluids can be determined by approximation of these flow curves with mathematical models. When the curve does not pass the zero point but intersects the $y$-axis (shear stress $\tau(\mathrm{Pa})$, Fig. 3$)$, one obtains yield shear stress $\tau_{0}$. 


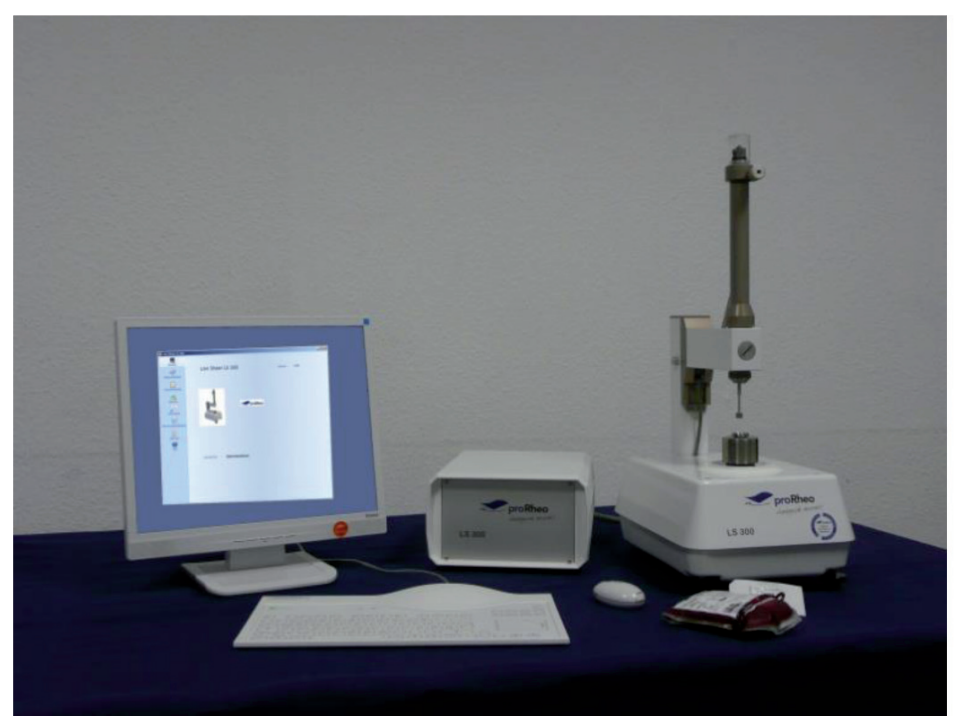

\section{Compensation system}

2 Light source

3 Mirror

4 Photo

-electric cell

5 Amplifier

6 Measuring bob

7 Measuring cup

8 Driveshaft

9 Transmitter

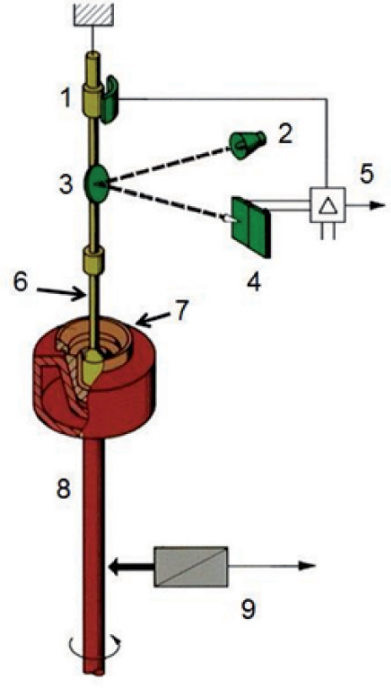

Figure 1. Photograph and schematic drawing of LS300 and its measuring principle. The thermostatically controlled measuring cup holder of the low shear viscosimeter LS300 is driven in accordance with the Couette principle. The test substance's torque causes - via the measuring bob - a minimum deflection of the frictionless suspended bob. A light beam reflected across a mirror is monitored by a photocell and amplified for transmission to the compensation system's coil. The current required for the zero point is proportional to the torque and, therefore, a function of shear stress. The bob as well as the cup can be easily replaced.

The sensitivity of the LS300 was tested by determination the temperature depending viscosity of water (ISO Technical Report 1998) at various shear rates between $10 \mathrm{~s}^{-1}$ and $100 \mathrm{~s}^{-1}$ in increments of $5 \mathrm{~s}^{-1}$ by increasing the temperature from $21^{\circ} \mathrm{C}$ up to $21.5^{\circ} \mathrm{C}$ in increments of $0.1^{\circ} \mathrm{C}$ (Fig. 2) (Berstad et al. 1988, Bauer et al. 1995). LS300 is highly sensitive for investigating the reduction of the viscosity of water by increasing temperature in gradients of $0.1^{\circ} \mathrm{C}$ within a range

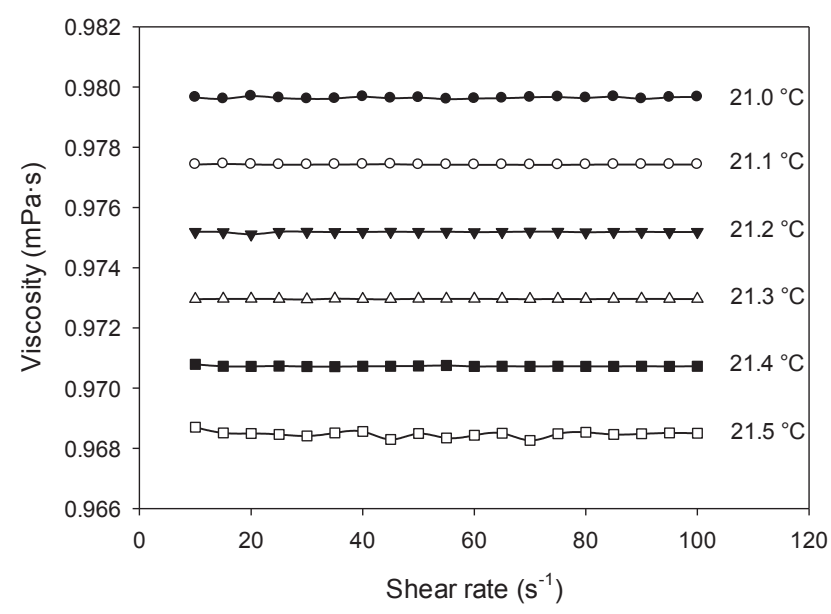

Figure 2. Viscosity of water at 21.0 to $21.5^{\circ} \mathrm{C}$. LS300 is highly sensitive. The deviation of theoretical viscosity values ( $y$-axis) ranges from 0 to $0.00023 \mathrm{mPa} \cdot \mathrm{s}$. of $21.0-21.5^{\circ} \mathrm{C}$. Deviation from the theoretical value was between 0 and $0.00023 \mathrm{mPa} \cdot \mathrm{s}$ (Fig. 2).

Whole blood was used to determine the viscosity of a non-Newtonian fluid. The viscosity of blood depends on the existing shear forces and is determined by hematocrit (hct), red blood cell (RBC) aggregation, plasma viscosity and the mechanical properties of RBCs (MarcinkowskaGapinska et al. 2007). At low shear rates aggregation of $\mathrm{RBC}$ and at high shear rates $\mathrm{RBC}$ deformability and orientation mainly influence the shape of the flow curve (Baskurt et al. 2003). Blood samples were taken from 10 healthy male non-smoking adults by slow and smooth aspiration after puncture of a cubital vein. Standard test tubes $(10 \mathrm{ml})$ coated with ethylenediaminetetraacetic acid $\left(\mathrm{C}_{10} \mathrm{H}_{16} \mathrm{~N}_{2} \mathrm{O}_{8}\right.$; EDTA; $\left.1.5 \mathrm{mg} / \mathrm{ml}\right)$ were filled with the blood. The determination of the hct was assessed using the microhematocrit method (Anwar et al. 1994). All preparations for the measurements were performed at the ambient temperature of $21^{\circ} \mathrm{C}$. All measurements were performed within three hours after blood sampling (Baskurt et al. 2009). The study was performed in accordance with the Declaration of Helsinki, and had been approved by the ethics committee of the University of Heidelberg. The blood samples were investigated by geometric distribution of twelve measuring points in a shear velocity range from $0.5 \mathrm{~s}^{-1}$ to $50 \mathrm{~s}^{-1}(0.5,0.76,1.16,1.76,2.67,4.06,6.16,9.37$, $\left.14.24,21.64,32.90,50 \mathrm{~s}^{-1}\right)$ within a time of $120 \mathrm{~s}$ and at a temperature of $37^{\circ} \mathrm{C}$. 
A

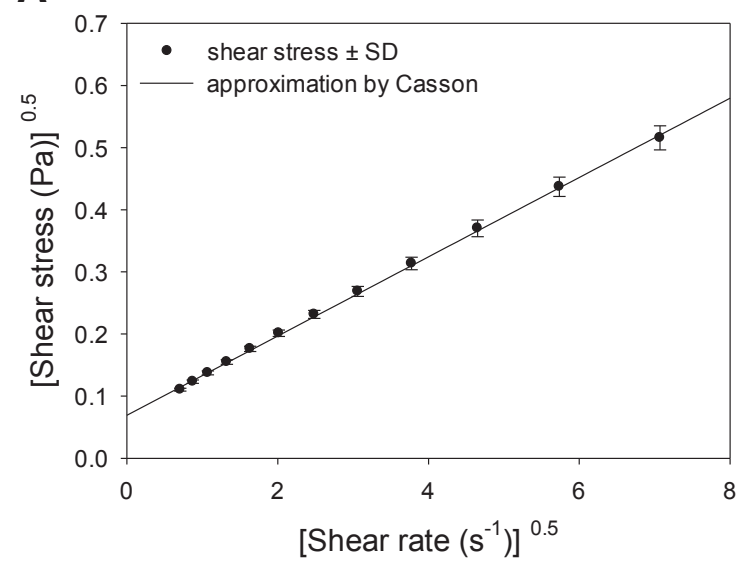

B

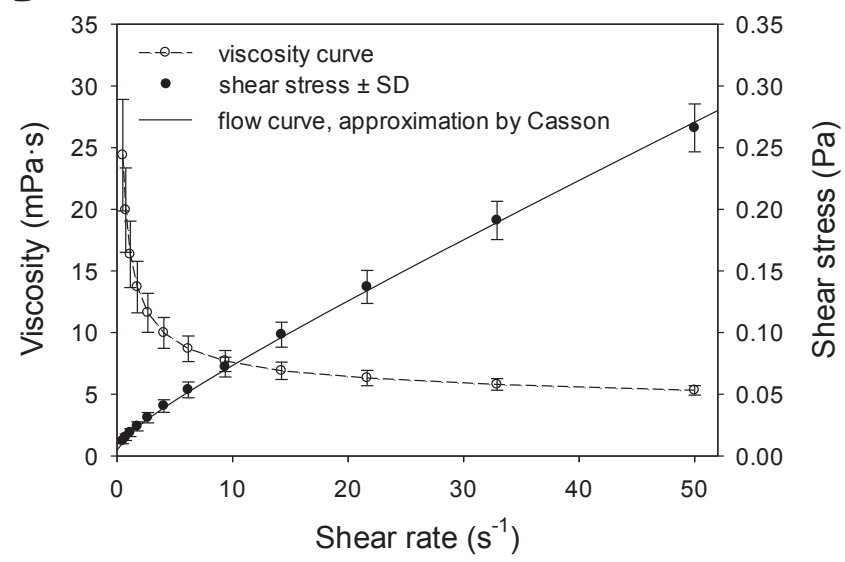

Figure 3. Flow curve (shear stress versus shear rate) of whole blood from ten healthy adult donors $\left(\mathrm{hct}=0.43(\mathrm{l} / \mathrm{l})\right.$; $\left.\mathrm{t}=37^{\circ} \mathrm{C}\right)$. Flow curve approximated by the chosen mathematical model, i.e. Casson; calculated parameters: $\tau_{0}=4.79 \mathrm{mPa} ; \eta_{\mathrm{Ca}}=4.07 \mathrm{mPa} \cdot \mathrm{s}$. A. Square root $(\sqrt{\tau})$ form of the figure of shear stress versus shear rate. B. Viscosity curve, flow curve approximated by Casson. Data are means \pm SD. hct, hematocrit; $\eta_{\mathrm{Ca}}=$ viscosity by Casson; $\tau_{0}$, yield shear stress.

For determination of the influence of RBC sedimentation rate (Matrai et al. 1984) in samples of whole blood during the measuring cycle (120 s), ten blood samples were investigated. The viscosity and shear stress of whole blood at a medium shear rate of $9.37 \mathrm{~s}^{-1}$ during the above mentioned measuring cycle after $79 \mathrm{~s}$ (viscosity $7.86 \pm 0.44 \mathrm{mPa} \cdot \mathrm{s}$; shear stress $0.074 \pm 0.0042 \mathrm{~Pa}$ ) and directly after filling the measuring chamber with a single shear rate of $9.37 \mathrm{~s}^{-1}$ (viscosity $7.91 \pm$ $0.30 \mathrm{mPa} \cdot \mathrm{s}$, shear stress $0.074 \pm 0.0027 \mathrm{~Pa}$ ) were compared. No significant differences were observed (Mann Whitney Rank Sum Test, whole blood viscosity $(p=0.80)$ and shear stress $(p=0.83)$. The $\mathrm{RBC}$ sedimentation rate did not play a significant role in our experimental setting with the LS300. By selecting many measuring points at low shear rates RBC sedimentation may be of importance.

To test the variability in determination of whole blood viscosity with the LS300 ten specimen of the same blood sample were used. We also determined blood viscosity by flow curves of specimen of 10 individuals. A sufficient approximation of the flow curve with a mathematical model was found by the model of Casson (Fig. 3):

Casson: $\sqrt{\tau}=\sqrt{\tau_{0}}+\sqrt{\eta_{C a} \cdot \dot{\gamma}}$

$\eta_{\mathrm{Ca}}$, viscosity by Casson; $\tau_{0}$, yield shear stress by Casson and transformed to $\tau(\dot{\gamma})$ as in the form of the plot (Fig. 3B):

$$
\tau=\tau_{0}+2 \sqrt{\tau_{0} \cdot \eta_{C a} \cdot \dot{\gamma}}+\eta_{C a} \cdot \dot{\gamma}
$$

Casson's model includes mention of yield shear stress $\tau_{0}$ (point of intersection of the flow curve and the y-axis) (Table 1) which is known to reflect RBC aggregation (Antonova et al. 2008). To apply the Casson's model over the whole range of shear rate affords special attention to the $\dot{\gamma}$ range. In the range below $10 \mathrm{~s}^{-1}$, we had to condense the measuring points (Fig. 3A). Otherwise the yield shear stress may be overestimated by the mathematical model. Other models for approximation of the flow curve and another selection of the

Table 1. Shear stress at given shear rate and approximation of viscosity and yield shear stress by Casson

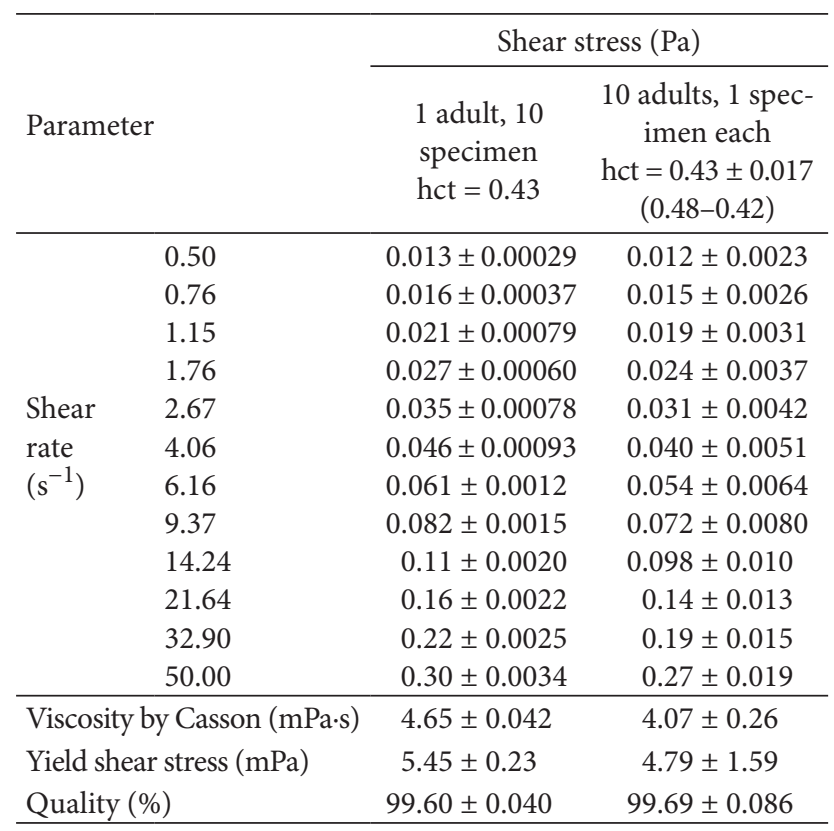

Data are means \pm SD. 
shear rate range and measuring points may further improve the determination of non-Newtonian fluids.

We found a good quality of agreement of $99.69 \%$ (Table 1) for the viscosity of whole blood of healthy adults by the approximation of Casson within the selected range and distribution of shear rates. The scattering of the ten specimen of one blood sample was smaller than that of the ten blood samples of the ten individuals (Table 1).

Blood viscosity is a major determinant of blood flow and tissue perfusion (Reinhart 2001). Elevated whole blood viscosity was found in patients with borderline essential hypertension (Letcher et al. 1983), diabetes (Tamariz et al. 2008) and in patients with silent cerebral infarction (Li et al. 2013). The determination of non-Newtonian whole blood viscosity could as well provide valuable information for improving perfusion management of cardiopulmonary bypass operation (Holsworth et al. 2013). Due to lowering body temperature and hemodilution during cardiac operation the blood viscosity can increase by 50 to $300 \%$. Optimization of the operative and postoperative management by optimal correction of whole blood viscosity for micro- and macrovasculature may minimize neurological complications and improve outcome.

\section{References}

Aarts P. A. M. M., Heethaar R. M., Sixma J. J. (1984): Red cell deformability influences platelets - vessel wall interaction in flowing blood. Blood 64, 1228-1233

Antonova N., Zvetkova E., Ivanova I., Savov Y. (2008): Hemorheological changes and characteristic parameters derived from whole blood viscometry in chronic heroin addicts. Clin. Hemorheol. Microcirc. 39, 53-61

Anwar M. A., Rampling M. W., Bignall S., Rivers R. P. (1994): The variation with gestational age of the rheological properties of the blood of the new-born. Br. J. Haematol. 86, 163-168 http://dx.doi.org/10.1111/j.1365-2141.1994.tb03268.x

Baskurt O. K., Meiselman H. J. (2003): Blood rheology and hemodynamics. Semin. Thromb. Hemost. 29, 435-450 http://dx.doi.org/10.1055/s-2003-44551

Baskurt O. K., Boynard M., Cokelet G. C., Connes P., Cooke B. M., Forconi S., Liao F., Hardeman M. R., Jung F., Meiselman H. J. et al. (2009): International Expert Panel for Standardization of Hemorheological Methods. New guidelines for hemorheological laboratory techniques. Clin. Hemorheol. Microcirc. 42, 75-97

Bauer H., Binas E., Broeke H., Völkel L. (1995): New recommended viscosity values for water as the metrological basis of viscometry. PTB-Mitteilungen 105, 99-105
Berstad D. A., Knapstad B., Lamvik M., Skjølsvik P. A., Tørklep K., Øye H. A. (1988): Accurate measurements of the viscosity of water in the temperature range $19.5^{\circ} \mathrm{C}-25.5^{\circ} \mathrm{C}$. Physica $\mathrm{A}$ 151, 246-280 http://dx.doi.org/10.1016/0378-4371(88)90015-5

Ernst E., Monshausen C., Matrai A. (1985): Blood viscosity - a comparitative study on three rotational instruments. Biorheology 22, 471-475

Holsworth Jr. R. E., Shecterle L. M., St. Cyr J. A., Sloop G. D. (2013): Importance of monitoring blood viscosity during cardiopulmonary bypass. Perfusion 28, 91-92 http://dx.doi.org/10.1177/0267659112463487

ISO Technical Report 3666 (1998): Viscosity of Water. International Organization for Standardization, 2nd Ed., Geneva

Letcher R. L., Chien S., Pickering T. G., Laragh J. H. (1983): Elevated blood viscosity in patients with borderline essential hypertension. Hypertension 5, 757-762 http://dx.doi.org/10.1161/01.HYP.5.5.757

Li R. Y., Cao Z. G., Wang R. T. (2013): Increased whole blood viscosity is associated with silent cerebral infarction. Clin. Hemorheol. Microcirc. (in press)

Marcinkowska-Gapinska A., Gapinski J., Elikowski W., Jaroszyk F., Kubisz L. (2007): Comparison of three rheological models of shear flow behavior studied on blood samples from post-infarction patients. Med. Bio. Eng. Comput. 45, 837-844 http://dx.doi.org/10.1007/s11517-007-0236-4

Matrai A., Flute P. T., Dormandy J. A. (1984): Improving accuracy of co-axial viscometry. Biorheology Suppl. 1, 99-101

Papaioannou T. G., Stefanadis C. (2005): Vascular wall shear stress: basic principles and methods. Hellenic J. Cardiol. 46, 9-15

Pop G. A. M., de Becker T. L. M., de Jong M., Struijk P. C., Moraru L., Chang Z., Goovaerts H. G., Slager C. J., Bogers A. J. J. C. (2004): On-line electrical impedance measurements for monitoring blood viscosity during on-pump heart surgery. Eur. Surg. Res. 36, 259-265 http://dx.doi.org/10.1159/000079910

Reinhart W. H. (2000): Molecular biology and self-regulatory mechanisms of blood viscosity: a review. Biorheology 38, 203-212

Shi Y. D., Agosti R., Ticozzelli P., Nasrawi F., Villa S., Somazzi R., Giovagnoni M. G., Longhini E. (1996): Hemorheological observation on 139 cases of essential hypertension by casson equation. Clin. Hemorheol. 16, 559-570

Tamariz L. J., Young H. Y., Pankow J. S., Yeh H.-C., Schmidt M. I., Astor B., Brancati F. L.(2008): Blood viscosity and hematocrit as risk factors for type 2 diabetes mellitus. The atherosclerosis risk in communities (ARIC) study. Am. J. Epidemiol. 168, 1153-1160 http://dx.doi.org/10.1093/aje/kwn243

Received: October 13, 2013

Final version accepted: February 14, 2014 